LOKABASA

Jurnal Kajian Bahasa, Sastra, dan Budaya Daerah serta Pengajarannya

Volume 10, No. 1, April - 2019, Hal. 34-42

p-2338-6193 (print) | e-2528-5904 (online)

Homepage: http://ejournal.upi.edu/index.php/lokabasa doi: $10.17509 / j l b . v 10 i 1$

\title{
Komunikasi Politik dan Budaya Damai di Zaman Galuh Pakuan dalam Konstelasinya di Masa Kini
}

\author{
Elis Suryani Nani Sumarlina, Rangga Saptya Mohamad Permana \\ Universitas Padjadjaran \\ elis.suryani@unpad.ac.id
}

\begin{abstract}
Sejarah Artikel: Diterima (06 Januari 2019); Diperbaiki (07 Maret 2019); Disetujui (20 Maret 2019); Pusblished (30 April 2019).

Bagaimana mengutip artikel ini (dalam gaya APA): Sumarlina, E.S.N. \& Rangga S.M.P. (2019). Komunikasi politik dan budaya damai di zaman Galuh Pakuan dalam konstelasinya di masa kini. Lokabasa, 10(1), 1-11. doi: 10.17509/jlb.v10i1.16930
\end{abstract}

\begin{abstract}
Abstrak: Naskah sebagai dokumen budaya tinggalan karuhun orang Sunda masa lampau, sungguh sangat melimpah dan masih sangat relevan untuk dikenalkan dan diungkap isinya pada masa kini. Kearifan lokal nilai-nilai yang terkandung dan terungkap dalam naskah, meliputi beragam aspek kehidupan masyarakat yang menyangkut tujuh unsur budaya Sunda, yakni: sistem religi atau kepercayaan, teknologi dan benda materiil, pemerintahan/kemasyarakatan, mata pencaharian hidup/ekonomi, ilmu pengetahuan/pendidikan, bahasa, dan seni. Harapan yang tersirat maupun tersurat dalam naskah-naskah yang diungkap dalam artikel ini masih terjalin adanya benang merah dengan kehidupan masyarakat Sunda saat ini, khususnya tentang komunikasi dan etika berpolitik", yang tentu saja tidak terlepas dari sumber daya manusia yang andal, yakni para pemangku kebijakan, pemerintahan, dan generasi muda sebagai pewaris bangsa. Artikel ini dipaparkan dan dikaji melalui metode penelitian deskriptif analisis, dengan melibatkan metode kajian filologis, historiografi, dan kajian budaya secara umum, yang diharapkan mampu mengungkap kearifan lokal sistem pemerintahan dan komunikasi politik yang terkandung dalam naskah Sunda abad XVI Masehi, konstelasinya dengan budaya Sunda masa kini.
\end{abstract}

Kata Kunci: Naskah; komunikasi politik; budaya damai

Political Communication and Peaceful Culture of Galuh Pakuan Era and its Current Constellation

Abstract: The manuscripts as cultural documents inherited from Sundanese past ancestors are plentiful and still very relevant to be introduced and revealed at the present. The values of local wisdom contained and revealed in the manuscript, covers various aspects of people's lives concerning the seven elements of Sundanese culture, i.e. religious systems or beliefs, technology, material items, government/society, livelihoods/economics, scienceleducation, language, and arts. The expectations implied and expressed in the texts revealed in this article are still intertwined with the current life of the Sundanese people, especially regarding communication and political ethics, which of course is inseparable from reliable human resources, those are the stakeholders, the government, and the young generation as heirs of the nation. This article is presented and examined through descriptive analytical research methods, involving philological study, historiography, and cultural studies methods in general, which are expected to be able to uncover the local wisdom of government system and political communication contained in the XVI century Sundanese manuscripts, and its constellation with current Sundanese culture.

Keywords: Manuscript; peaceful culture; political 


\section{PENDAHULUAN}

Kearifan lokal budaya yang dimiliki oleh setiap suku bangsa, tersirat lewat tinggalan budaya karuhun 'nenek moyang' para pendahulunya. Demikian halnya dengan karuhun orang Sunda, yang menyimpan beragam ide, gagasan, filsafat hidup, dan pemikiran cemerlang, yang dapat dijadikan acuan serta masih sejalan dengan kehidupan masa kini. Salah satu tinggalan masa lalu dimaksud, khususnya yang berkaitan dengan tata pemerintahan dan budaya Damai.

Sistem pemerintahan dan tata pemerintahan di negeri kita, selama ini mengacu pada teori Montesque yang dikenal dengan istilah Trias Politica, yang terdiri atas eksekutif, legeslatif, dan yudikatif. Eksekutif dalam hal ini dipegang oleh Presiden. Legislatif dipegang oleh Dewan Perwakilan Rakyat. Sedangkan yudikatif dipegang oleh Mahkamah Agung. Orang awam selama ini menganggap bahwa sistem pemerintahan berdasarkan Trias Politica itu merupakan adopsi dari luar negeri. Benarkah? Mengapa kita selalu menganggap bahwa segala sesuatu itu berasal dari mancanegara? Apakah bangsa kita tidak mampu dan tidak memiliki kearifan lokal yang bisa dibanggakan oleh bangsa kita sendiri?

Tulisan ini ditengarai akan sangat panjang andai memaparkan kesejarahan, religi, etika, politik, komunikasi, seni, sastra, hukum, obat-obatan tradisional, maupun pertanian, yang terungkap dalam naskah Sunda, karena ruang lingkupnya terlalu luas. Selain itu, ada pertanyaan yang muncul, kesejarahan apa yang dimaksud? Apakah sejarah yang berhubungan dengan perkembangan naskah, aksara, bahasa, atau pembabakan zaman dan isi yang terkandung di dalamnya? Karena itu, sesuai dengan isinya, maka secara khusus artikel ini diarahkan kepada pemaparan nilai-nilai kearifan lokal budaya Sunda yang terpendam dalam naskah, khususnya yang berkaitan dengam komunikasi dan etika berpolitik Masyarakat Sunda, ditinjau dari Kajian Filologi atau tradisi tulis, yang terungkap dalam naskah Sunda, terutama naskah-naskah Sunda kuno abad ke-16 Masehi, yang kurang atau bahkan mungkin belum dikenal oleh masyarakat Sunda secara luas dan menyeluruh, apalagi gererasi mudanya. Diharapkan dapat menambah wahana pengetahuan untuk berbagai disiplin ilmu dan masyarakat secara umum, agar peduli terhadap peninggalan warisan-warisan budaya Sunda yang sangat berharga.

\section{Sekilas Komunikasi Politik}

Pengertian Komunikasi Politik menurut Maswadi Rauf (dalam Harun \& Sumarno, 2006: 3) menempatkan komunikasi politik sebagai objek kajian ilmu politik, karena pesan-pesan yang disampaikan dalam proses komunikasi bercirikan politik, yaitu bersifat kekuasaan politik negara, pemerintahan dan aktivitas komunikator dalam kedudukannya sebagai pelaku kegiatan politik. Nimmo (dalam Ardial, 2010: 28) merumuskan komunikasi politik sebagai kegiatan yang bersifat politis atas dasar konsekuensi aktual dan potensial, yang menata perilaku dalam kondisi konflik.

Pengertian komunikasi politik lainnya datang dari Mark Roelofs dan Barn Lund (dalam Harun \& Sumarno, 2006: 5) yang menyatakan bahwa "Politics is talk or to put the matter, more exactly the activity of politics (politicking) is talking". Dari ungkapan tersebut, meskipun dalam kalimat yang sangat sederhana, namun menyiratkan bahwa komunikasi politik lebih memusatkan kajiannya pada bobot materi muatan yang berisi pesan-pesan politik (isu politik, peristiwa dan perilaku politik individu-individu baik sebagai penguasa maupun yang berada dalam asosiasi-asosiasi kemasyarakatan atau asosiasi politik).

Berdasarkan pemaparan-pemaparan di atas, kami menyimpulkan bahwa 
komunikasi politik adalah proses penyampaian/pertukaran pesan dari komunikator kepada komunikan yang isi pesannya mengandung faktor-faktor kekuasaan, pemerintahan atau isu-isu yang dikeluarkan oleh para pemegang kekuasaan. Komunikasi politik juga bisa dipahami sebagai komunikasi antara "yang memerintah" dan "yang diperintah" (Saptya MP \& Suryani NS, 2019).

Dalam komunikasi politik, istilah yang dimaksud dengan komunikator politik adalah individu-individu yang menduduki struktur kekuasaan, individu-individu yang berada dalam suatu institusi, asosiasi, partai politik, lembaga-lembaga pengelola media massa dan tokoh-tokoh masyarakat. Komunikator politik dapat pula berupa negara, badan-badan internasional dan mereka yang mendapat tugas atas nama negara (Harun \& Sumarno, 2006: 11). Singkatnya, komunikator politik adalah individu atau sekelompok individu yang menyampaikan pesan yang berkaitan dengan kekuasaan dan kebijakan/aturan/ kewenangan pemerintah yang bertujuan untuk memengaruhi khalayak.

Komunikator dalam komunikasi politik, yaitu individu-individu yang menduduki struktur kekuasaan, karena merekalah yang mengelola, mengendalikan lalu lintas transformasi pesan-pesan komunikasi dan mereka yang menentukan kebijaksanaan komunikasi nasional. Karena itu, sebagai komunikator politik dituntut berbagai persyaratan agar proses komunikasi mencapai sasaran sebagaimana yang diharapkan (Harun \& Sumarno, 2006: 11). Persyaratan-persyaratan tersebut yakni 1) memiliki nuansa yang luas tentang barbagai aspek dan masalah-masalah kenegaraan, 2) memiliki komitmen moral terhadap sistem nilai yang sedang berlangsung, 3) berorientasi kepada kepentingan negara, 4) memiliki kedewasaan emosi (emotional intellegence), dan 5) Jauh dari sikap hipokrit (cognitive dissonance).
Nimmo (2005: 30) membagi komunikator politik menjadi 3 jenis, yakni politikus, profesional, dan aktivis. Politikus adalah individu yang memegang jabatan pemerintah (baik itu eksekutif, legislatif, maupun yudikatif). Politikus ini memiliki pengaruh terhadap alokasi ganjaran, bisa menuntun/mencegah perubahan sosial, dan bisa memengaruhi pembentukan opini publik di masyarakat. Politikus sendiri terbagi menjadi dua, yakni partisan dan ideolog. Partisan adalah anggota dari sebuah partai politik, sedangkan ideolog adalah orang yang berpikir; "menjual" idenya untuk masa depan bangsa dan negara.

Istilah profesional dalam artikel ini bisa diartikan sebagai orang yang menjadikan komunikasi sebagai nafkah pencahariannya, baik di dalam maupun di luar politik, yang muncul akibat revolusi komunikasi, seperti munculnya media massa lintas batas dan perkembangan sporadis media khusus (majalah internal, radio siaran, dsb.) yang menciptakan publik baru untuk menjadi konsumen informasi dan hiburan. Profesional disebut juga makelar simbol yaitu orang yang menerjemahkan sikap pengetahuan dan minat suatu komunikasi bahasa ke dalam komunitas bahasa lain yang berbeda tetapi menarik dan dapat dimengerti. Komunikator profesional ini meliputi jurnalis (wartawan, penulis) dan promotor (humas, juru bicara, juru kampanye, dsb). Sedangkan aktivis politik adalah orang yang terjun ke dalam politik hanya sebatas part time (dalam waktu senggang), maka disebut juga volunteer atau sukarelawan. Aktivis politik terdiri dari dua jenis, yaitu juru bicara dan pemuka pendapat.

Penelitian naskah yang berkaitan dengan sistem pemerintahan, etika, komunikasi, politik, beserta aspek lainnya, masih jarang dilakukan. Penelitian filologi masih sebatas transliterasi, edisi teks, dan terjemahan. Jadi, penulis sulit untuk mendapatkan hasil penelitian yang khusus tentang kajian dimaksud. Namun paling 
tidak, ada beberapa skripsi, tesis, dan disertasi, juga tulisan yang mengungkap tentang masalah yang dibahas dalam artikel ini, terutama artikel-artikel yang ditulis Suryani NS, dalam beberapa surat kabar dan majalah, juga makalah dan buku Senarai Kearifan Lokal Budaya Sunda dalam Media Massa Cetak jilid 1 \& 2 (2018). Di samping itu, beberapa nukilan makalah dan artikel serta buku karya Ekadjati dan Darsa.

\section{METODE}

Mengingat cukup banyak model penelitian, maka perlu ditegaskan bahwa pemilihan serta penentuan suatu metode harus disesuaikan dengan objek dan teksteks yang sudah dinilai dapat digunakan untuk penelitian selanjutnya untuk diperiksa keasliannya (eksaminasi); apakah ada tempat yang korup, apakah ada bagian dan teks yang ditanggalkan (lakuna), apakah ada tambahan (interpolasi) dari penyalin-penyalin kemudian, dan ketidaksempurnaan lainnya. Di samping itu, dan bacaan teks-teks lain dicatat semua tempat yang berbeda sesuai dengan prosedur penelitian filologi.

Metode penelitian menyangkut masalah cara kerja untuk mewujudkan sebuah bentuk hasil penelitian yang telah dilakukan. Biasanya disajikan mulai dari tahap yang bersifat deskriptif, analisis, komparatif, dan sebagainya. Metode penelitian yang digunakan biasanya disesuaikan dengan tujuan dan objek (naskah) yang diteliti. Sehubungan dengan itu, metode penelitian yang digunakan adalah metode deskriptif analisis.

Metode deskriptif analisis dimaksudkan untuk mencatat, menuturkan, menafsirkan, menganalisis, serta membandingkan data melalui suatu proses pemahaman yang akan sangat bergantung pada keadaan data dan nilai bahan atau objek penelitian yang digarap. Untuk itu perlu ditempuh langkah-langkah pengumpulan data berupa naskah yang memuat objek data naskah yang dikaji, yang dilaksanakan berdasarkan informasi hasil studi pustaka, antara lain melalui katalog-katalog naskah.

Langkah selanjutnya, ditentukan metode kritik teks yang paling sesuai dengan hasil perbandingan hasil teks dan tujuan penelitian. Berdasarkan hal tersebut, maka metode kajian yang digunakan dalam tulisan ini adalah metode kajian kritik teks secara filologis, dan kajian budaya serta komunikasi politik, yang berkaitan dengan unsur-unsur naskah yang di dalamnya mengungkap etika, sistem pemerintahan, kepemimpinan, dan komunikasi berpolitik para pemangku kebijakan di masyarakat.

Studi lapangan dilakukan di tempattempat penyimpanan naskah baik yang ada di perpustakaan, di museum-museum, termasuk pula informasi tentang naskahnaskah yang terdapat di luar negeri. Pengolahan data dilakukan dengan jalan mendeskripsikan naskah yang diteliti, yang meliputi keseluruhan aspek naskah sesuai dengan pola baku filologi dan kajian budaya.

Teknik pengumpulan sumber data, baik sumber data primer maupun sumber data sekunder, dalam penelitian ini ditempuh dengan cara studi pustaka dan kerja lapangan.

Studi Pustaka (library research) yang bertujuan untuk mencari atau mendapatkan artikel-artikel serta sumber-sumber tertulis yang tersimpan di perpustakaan atau di mana tempat dokumen itu tersimpan, yang ada kaitannya dengan teks naskah yang di dalamnya mengungkap sistem pemerintahan, etika, kepemimpinan, komunikasi, politik dan budaya secara umum.

Studi Lapangan (field research), yaitu mencari naskah yang ada atau tersimpan di masyarakat secara perseorangan, sebagai milik pribadi, di samping mengumpulkan informasi lisan untuk menunjang penelitian. Pengumpulan keterangan ini cukup penting untuk menelusuri wacana teks naskah, hubungannya dengan etika, sistem pemerintahan, 
kepemimpinan, komunikasi, politik dan budaya.

\section{HASIL DAN PEMBAHASAN}

Naskah Fragmen Carita Parahyangan (FCP) merupakan salah satu naskah Sunda buhun bernuansa historis dari abad ke-16 Masehi, yang tersimpan dalam kropak 406 bersama dengan naskah Carita Parahyangan $(C P)$, dan kini disimpan di Bagian Koleksi Naskah Perpustakaan Nasional Jakarta. Jumlah lempir halaman keseluruhan terdiri atas 47 buah, yang masing-masing berukuran 21 x $3 \mathrm{~cm}$. Secara garis besar menyajikan gambaran sistem pemerintahan dan tatapemerintahan kerajaan Sunda yang berpusat di ibukota Galuh Pakuan Pajajaran.

Naskah Fragmen Carita Parahiyangan mengungkap Sistem pembagian kekuasaan yang disebut Tri Tangtu di buana 'tiga unsur penentu kehidupan di dunia', terdiri atas Prabu, Rama dan Resi. Prabu adalah pemimpin roda pemerintahan (eksekutif yang saat ini dipegang oleh pemerintah, dalam hal ini presiden) yang harus ngagurat batu 'berwatak teguh'. Rama adalah golongan yang dituakan sebagai wakil rakyat (legislatif atau Dewan Perwakilan Rakyat) yang harus ngagurat lemah 'berwatak menentukan hal yang mesti dipijak'. Resi adalah golongan yang bertugas memerdayakan hukum agama dan darigama 'negara' (yudikatif atau saat ini dipegang oleh Mahkamah Agung dan Alim Ulama) yang harus ngagurat cai 'berwatak menyejukkan dalam peradilan'.

Tatapemerintahan yang tercermin dalam Naskah Fragmént Carita Parahiyangan, hingga saat ini masih bisa kita lihat melalui sistem pemerintahan masyarakat Baduy (Kanékés), yang dipimpin oleh tiga kapuunan, yakni Puun Cikeusik, Puun Cikartawana, dan Puun Cibéo. Sistem pembagian kekuasaan yang dikenal dengan istilah Tri Tangtu di Buana tersebut, dalam sistem pemerintahan masyarakat Baduy unsur prebu atau yang bertindak sebagai pemimpin roda pemerintahan (eksekutif) dipegang oleh Puun Cibéo. Rama sebagai golongan yang dituakan atau wakil rakyat (legislatif) dipegang oleh Puun Cikartawana. Sedangkan Resi yang bertugas memberdayakan hukum agama dan darigama 'negara' (yudikatif) dipegang oleh Puun Cikeusik (Suryani NS, 2018).

Tata pemerintahan dalam masyarakat Tatar Sunda masa silam sebagaimana yang diimplementasikan oleh masyarakat Baduy, tampak selaras dan harmonis. Antara Prabu, Rama, dan Resi paheuyeukheuyeuk leungeun 'bersinergi dan saling membantu', teu pakia-kia 'tidak gontokgontokan dan tidak bertolak belakang satu sama lain'. Di samping itu, ketiga unsur tersebut dalam hal-hal tertentu saling menghormati satu sama lainnya, sesuai dengan tugas dan fungsinya. Pihak Prabu teu pacorok kokod 'tidak akan ikut campur' terhadap kekuasaan Rama dan Resi, demikian juga sebaliknya. Namun untuk membicarakan segala sesuatu yang berkaitan dengan kehidupan dan adat istiadat juga tradisi dan kepercayaan dalam komunitas Baduy, ketiganya senantiasa berembug dan bermufakat untuk kebaikan bersama.

Tata pemerintahan masyarakat Tatar Sunda di masa silam, merupakan salah satu penjelmaan dari sistem pemerintahan masyarakat Sunda mangsa bihari 'masa lampau', sebagaimana tercermin dalam naskah Fragmént Carita Parahiangan, yang mampu memberikan gambaran bahwa masyarakat Tatar Sunda di masa silam telah memiliki satu taraf kehidupan sosial yang cukup teratur. Hal ini pun membuktikan bahwa kecerdasan Nenek Moyang orang Sunda jaman dahulu tidak kalah pandai dan mampu melebihi kecerdasan masyarakat lainnya, karena Karuhun Orang Sunda telah menggunakan Sistem Tatapemerintahan Tatar Sunda sejak abad ke15 dan 16 Masehi (Saptya MP, \& Suryani NS, 2019).

Sistem pemerintahan dan sistem pembagian kekuasaan masyarakat Sunda 
masa lampau, selain masih diimplementasikan di Kanekes Baduy Banten, juga masih tampak dan digunakan oleh masyarakat adat Kampung Naga Tasikmalaya, yang dikenal dengan sebutan Tri Tangtu Di Bumi, yang meliputi tatalampah, tatawayah, dan tatawilayah. Ketiga istilah tersebut diejawantahkan dalam kehidupan masyarakat sehari-hari dan menjadi pedoman hidup dalam berperilaku, bertani, berdagang, dan mencari nafkah, serta menjaga dan melestarikan lingkungan hidup (Suryani NS, 2018).

Upaya musyawarah dan perdamaian antarumat di antara pihak yang sedang berseteru, sudah tampak sejak zaman Kerajaan Sunda di masa lalu, yang tentu saja melibatkan tiga unsur penentu pemerintahan saat itu, antara Prabu, Rama, dan Resi. Salah satunya upaya perdamaian antara para pembesar di masa Kerajaan Galuh, yang dilakukan oleh Pembesar Kerajaan Galuh dengan Kerajaan Medang Mataram Kuno, yang berlangsung di Galuh Pakwan, tahun 740 Masehi (tahun 661 Saka bulan Phalguna, tanggal 15 Paroterang atau tanggal 8 Maret 740 Masehi).

Sistem Tatapemerintahan Tri Tangtu Di Buana berkaitan erat dengan tinggalan kearifan lokal budaya Sunda lainnya yang tersimpan lewat prasasti, yang isinya selain mengungkap nasihat, pesan moral, falsafah, kearifan, kebajikan, persatuan, juga kerukunan hidup bermasyarakat dan bernegara agar damai, tentram, adil, dan bijaksana, sebagaimana terungkap dalam Prasasti Kawali, yang berada di Astana Gede Kabuyutan Kawali, Kabupaten Ciamis yang salah satunya telah diimplementasikan melalui Gong Perdamaian Abadi yang ada di Karang Kamulyan Ciamis.

Keberadaan Gong Perdamaian tersebut tentu saja tidak terlepas dari Karang Kamulyan sebagai salah satu patilasan Kerajaan Galuh, serta Kabuyutan Kawali yang menyimpan beragam patilasan serta peninggalan karuhun orang Sunda di masa lampau, sebagaimana terungkap melalui amanat dan pesan Prabu Niskalawastu Kancana, sebagaimana tersirat lewat Prasasti Kawali dan Prasasti Batu Tulis Bogor.

Mengapa Gong Perdamaian diletakkan di kawasan wisata Karang Kamulyan? Secara historis maupun folklor yang berkembang di sekitar Karang Kamulyan, juga kaitannya dengan prasasti dan patilasan karuhun orang Sunda masa lampau, hal itu sejalan dengan visi dan misi awal dari pembuatan 'Gong Perdamaian Dunia' itu sendiri. Apabila kita simak cerita lisan Karang Kamulyan/Carita Ciung Wanara, kita bisa mencermati bahwa pertikaian antara Ciung Wanara dan Hariyang Banga (keduanya saudara sebapak lain ibu), ternyata dapat didamaikan oleh 'Sang Prabu' (ayah kandung mereka sendiri) yang menyamar menjadi seorang 'kakek'.

Pertikaian antara Ciung Wanara dan Hariyang Banga (dalam versi lain disebut Sanjaya) merupakan satu-satunya perkelahian pada masa lampau, yang mampu 'didamaikan'. Karena jika dicermati, kebanyakan dari kisah dan pertikaian antar kerajaan dan seuweu siwi 'keturunannya'itu selalu berakhir dengan kehancuran tanpa perdamaian. Hal itulah yang menjadi salah satu alasan tujuan didirikannya Gong Perdamaian Dunia di Karang Kamulyan Ciamis.

Jika kita cermati amanat Prabu Niskalawastu Kancana sebagaimana terungkap dalam Prasasti Kawali 1 hingga 6, Beliau adalah seorang raja yang mumpuni, adil bijaksana, disegani serta dicintai rakyatnya. Beliau telah mampu ngretakeun urang reya 'memberdayakan \& mensejahterakan orang banyak' atau ngretakeun bumi lamba 'mensejahterakan alam dunya' (menurut Sanghyang Siksakandang Karesian), sehingga Beliau termasuk salah satu raja besar Sunda yang digelari Prabu Siliwangi (raja yang harum namanya).

Amanat dan pesan moral yang tersirat dalam prasasti Kawali, bukan hanya 
memberi makna kesejahteraan, kearifan, kejujuran, dan kerukunan hidup, namun juga kedamaian serta kesatuan berbangsa, bernegara, serta beragama. Tuntunan moral yang Beliau ungkapkan lewat amanat bagi anak cucu dan rakyatnya yang mendiami Kawali serta Galuh (Ciamis sekarang) masih sangat relevan bagi kehidupan masa kini, salah satunya adalah bahwa kita sebagai manusia tidak boleh serakah jika tidak ingin sengsara di kemudian hari "ulah botoh bisi kokoro" sebagaimana terungkap lewat Prasasti Kawali 6. Keserakahan tersebut bukan hanya terbatas pada materi semata, tetapi lebih kepada semua hal yang menyangkut hajat hidup orang banyak (Suryani NS, 2018).

Sepatutnya kebajikan, kejujuran, kearifan, keutuhan dan persatuan bangsa serta kerukunan beragama, dan kedamaian, layak untuk diabadikan dalam upaya memelihara keutuhan dan persatuan umat, agar nonoman Sunda 'generasi muda Sunda' tidak pareumeun obor 'kehilangan jejak' serta kehilangan jati dirinya. Sudah seharusnya pula kita berupaya ngawanohkeun 'mengenalkan' kembali patilasan dan sejarah karuhun orang Sunda masa lalu, yang terpendam dalam naskah Sunda kuno tersebut, agar ajén inajén dan jati diri ' $\mathrm{Ki}$ Sunda' tetap lestari, bahkan digali dan dikaji, agar terungkap isi yang terkandung di dalamnya.

Pembuatan Gong Perdamaian Dunia diharapkan agar kita senantiasa damai di bumi dan damai di hati, sebagaimana diajarkan oleh semua agama di dunia ini. Ikan Kumpay yang berada di kolam depan monumen tersebut pun melambangkan perdamaian, sebagai pengingat agar Tatar Sunda cinta damai, di samping cinta lingkungan, bangsa, dan agama. Sebagaimana tercermin dalam visi dan misi Hari Perdamaian Dunia yang diperingati setiap tanggal 21 September.

Pembeberan informasi berkaitan dengan sistem tatapemerintahan dan budaya damai Tatar Sunda dari serpihan- serpihan terpendam naskah dan prasasti dalam tulisan ini, diharapkan menjadi pemantik dan penarik perhatian bagi generasi muda. Setidaknya untuk dapat mencermati kearifan lokal budaya Sunda yang tercermin dalam tradisi tulis dan tradisi lisan, yang secara tidak langsung tidak hanya akan memberikan kebanggaan dan jati diri masyarakat Sunda, tetapi juga keteguhan untuk memelihara, melestarikan dan mengolah nilai-nilai luhur kearifan lokal budaya masa silam yang sangat berharga serta tidak bisa diukur dan dinilai dengan materi semata.

Sebuah ide cemerlang dan karya monumental dari seorang pemerhati budaya yang notabene seorang perwira polisi saat menjabat sebagai Kapolwil Priangan dan mantan Kapolda Jawa Barat bernama Irjen Pol. Dr. H. Anton Charliyan, MPKN itu masih berdiri kokoh dan menakjubkan serta memesona, meski sudah berusia 10 tahun. Monumen yang berdiri megah di kawasan wisata Karang Kamulyan Kabupaten Ciamis dimaksud adalah Gong Perdamaian Dunia, berukuran 3,33 meter persegi, terbuat dari perunggu dan plat besi, yang di sekelilingnya dihiasi bendera, sebagai lambang ras serta agama sedunia.

Gong Perdamaian Dunia Karang Kamulyan dikerjakan oleh Dr. Djojoto Suntani. Di belakang gong besar itu terdapat keris pusaka peninggalan Kuda Lalean disertai batu-batu yang berasal dari Kawali. Gong Perdamaian Dunia ini diresmikan tanggal 9 bulan 9 tahun 2009, tepat jam 09.09. Ukuran GPD, jika dikalikan 3,33 x 3 adalah 9,9, sesuai dengan waktu peresmiannya (Suryani NS, 2018).

Gong Perdamaian Dunia yang ada di Karang Kamulyan, ada kaitannya dengan sejarah perdamaian masa silam di Keraton Galuh Pakwan antara Pembesar Galuh dan Medang Mataram Kuno yang berlangsung pada tahun 740 Masehi. Perdamaian di Galuh Pakwan terlaksana, berkat kewibawaan Sang Resiguru Demunawan, yang mampu menghentikan konflik di Galuh, walaupun saat itu baru saja tiba 
pasukan Bhairawamamuk dan pasukan Bhatarakroda dari Medang Mataram.

Atas inisiatif dan pimpinan Sang Resiguru Demunawan atau Seuweukarma diadakanlah musyawarah di istana Galuh Pakwan, antara para pembesar dari kedua belah pihak. Musyawarah tersebut menghasilkan "sepuluh kesepakatan" yang diwujudkan dalam bentuk perjanjian, yang ditulis pada tahun 661 Saka bulan Phalguna tanggal 15 paroterang atau 8 Maret 740 Masehi. Perjanjian itu pun dihadiri dan disepakati oleh para petinggi dan para pejabat pada masa itu.

Kearifan lokal yang berkaitan dengan masalah kedamaian, kebajikan, kejujuran, keutuhan dan persatuan bangsa serta kerukunan beragama, yang terungkap dalam naskah Sunda kuno, layak untuk diabadikan dalam upaya memelihara keutuhan dan persatuan umat, agar nonoman Sunda 'generasi muda Sunda' tidak pareumeun obor 'kehilangan jejak' serta kehilangan jati dirinya.

Isi perdamaian tersebut menurut (Darsa, 2018) adalah bahwa a) Permusuhan di antara kedua belah pihak diakhiri; mereka saling memaafkan, saling menolong, saling membantu, dan bersahabat; b). Tidak boleh melakukan pembalasan di antara mereka, karena berasal dari satu nenek moyang; semua anggota kesatuan bersenjata yang tertawan dibebaskan; c) Apabila terjadi pertentangan di antara mereka hendaklah diselesaikan secara damai melalui perundingan; hubungan kekerabatan di antara mereka janganlah putus; janganlah satu negeri menundukan negeri yang lainnya; hendaklah saling mengasihi dan saling menyayangi; d) Raden Kamarasa alias Rahiyang Banga (cucu Sang Sanjaya) diangkat menjadi Raja Sunda dengan gelar Prabhu Kretabhuawana Yasawiguna Hajimulya yang bertahta di Pakwan Pajajaran; wilayah kekuasaannya ialah dari Sungai Citarum ke sebelah barat; e) Raden Sorottoma alias Rahiyang Manarah diangkat menjadi Raja Sunda dengan gelar
Prabhu Jayaprakosa Mandhaleswara Sakalabhuawana yang bertahta di Galuh Pakwan; wilayah kekuasaannya ialah dari Sungai Citarum ke sebelah timur; Perjanjian selanjutnya f) Resiguru Demunawan menjadi Prabhu Resiguru Saunggalah di bumi Galuh Pakwan. Saunggalah menjadi daerah bebas pajak, daerah agama, daerah merdeka; Sang Sanjaya tetap menjadi raja Medang di bumi Mataram. Putra ke-2 Sang Jatmika alias Rahiang Sempakwaja (petinggi kaum rama di Kabataraan Galunggung); g) Perdagangan dan penangkapan ikan diizinkan secara terbuka; penjagaan pantai laut dilakukan oleh angkatan bersenjata masing-masing dan tapal batasnya dijaga secara bersama; h) Tempat-tempat peribadatan keagamaan dan tempat penyembahan harus dihormati bersamasama, termasuk semua benda yang diperlukan dalam upacara peribadatan; i) Adat kebiasaan warga masyarakat pribumi setempat harus dilindungi; j) Wilayah tempat tinggal Resiguru Demunawan harus dihormati oleh mereka; janganlah ada yang berkhianat terhadap perjanjian kaum keluarga ini (Darsa, 2018).

Surat perjanjian itu disepakati dan ditandatangani oleh 4 orang petinggi kerajaan, yaitu Resiguru Demunawan, Sang Sanjaya, Sang Manarah, dan Sang Banga. Sementara itu, turut menandatangani sebagai saksi ialah 7 orang pembesar kerajaan; yang terdiri atas 4 orang pejabat pemerintahan, masing-masing bernama Sang Panangkaran, Patih Balangantrang, Sang Kretayudha, Panglima Langlangsebrang; dan 3 orang pejabat agama, yaitu Sang Dharmādyaksa agama: Siwa, Wisnu, dan Budha (Darsa, 2018).

\section{SIMPULAN}

Kepemimpinan (parigeuing), kedamaian, kebajikan, kejujuran, keutuhan dan persatuan bangsa serta kerukunan beragama, yang tersimpan dalam naskah Sunda Kuno abad ke-16 Masehi, layak untuk digali, diteliti dan dikaji, serta 
dikembangkan dan diabadikan dalam upaya memelihara keutuhan dan persatuan umat, agar nonoman Sunda 'generasi muda Sunda' tidak pareumeun obor 'kehilangan jejak' serta kehilangan jati dirinya. Sudah sepatutnya kita ngawanohkeun 'mengenalkan' kembali patilasan 'tinggalan' dan sejarah karuhun 'nenek moyang' orang Sunda masa lampau, agar ajén inajén dan jati diri 'Ki Sunda' tetap lestari.

\section{UCAPAN TERIMA KASIH}

Penulis mengucapkan terima kasih kepada tim penyunting jurnal Lokabasa atas dipublikasikannya tulisan ini.

\section{CATATAN PENULIS}

Penulis menyatakan bahwa tidak ada konflik kepentingan terkait publikasi artikel ini. Penulis mengkonfirmasi bahwa data dan artikel ini bebas plagiarisme.

\section{PUSTAKA RUJUKAN}

Ardial. (2010). Komunikasi Politik. Jakarta: Indeks.

Darsa, U. A. dkk. (2018). Lintas Budaya Nusantara dalam Perspektif Kajian Multidisiplin Bandung: PT. Raness Media Rancage.
Harun, R. \& Sumarno, A.P. (2006). Komunikasi Politik sebagai Suatu Pengantar. Bandung: Mandar Maju.

Nimmo, D. (2005). Komunikasi Politik: Komunikator, Pesan, dan Media. Terjemahan Tjun Surjaman. Bandung: Remaja Rosdakarya.

Saptya M.P, Rangga \& Elis S.N.S. (2019). Komunikasi Politik Berbasis Naskah Sunda Kuno Abad XI M. Bandung: PT. Raness Media Rancage.

Suryani N.S., Elis. (2017). Mengungkap Serpihan Terpendam Budaya Kampung Naga. Bandung: SituSeni \& PT. Raness Media Rancage.

Suryani N.S., Elis. (2018a). Baduy Masa Kini: Antara Konvensi dan Inovasi. Bandung: SituSeni \& PT. Ranes Media Rancage.

Suryani N.S., Elis. (2018b). Senarai Kearifan Lokal Budaya Sunda dalam Media Massa Cetak 1. Bandung: PT. Ranes Media Rancage.

Suryani N.S., Elis. (2018c). Senarai Kearifan Lokal Budaya Sunda dalam Media Massa Cetak 2. Bandung: PT. Ranes Media Rancage.

Suryani N.S., Elis. (2018d). Seni Budaya dan Kearifaa Lokal. Bandung: PT. Ranes Media Rancage. 